\title{
The duration of SIRS before organ failure is a significant prognostic factor of sepsis
}

\author{
Hiroki Sugita ${ }^{1 *}$, Yoshihiro Kinoshita ${ }^{2}$ and Hideo Baba ${ }^{1}$
}

\begin{abstract}
Background: The mortality rate of patients complicated with sepsis-associated organ failure remains high in spite of intensive care treatment. The purpose of this study was to define the duration of systemic inflammatory response syndrome (SIRS) before organ failure (DSOF) and determine the value of DSOF as a prognostic factor in septic patients.

Methods: This retrospective cohort study was conducted in an 11-bed medical and surgical intensive care unit (ICU) in a university hospital. The primary endpoint was in-hospital mortality of the septic patients.

Results: One hundred ten septic patients with organ failure and/or shock were enrolled in this study. The in-hospital mortality rate was $36.9 \%$. The median DSOF was $28.5 \mathrm{~h}$. As a metric variable, DSOF was a statistically significant prognostic factor according to univariate analysis (survivor: $74.7 \pm 9.6 \mathrm{~h}$, non-survivor: $58.8 \pm 16.5 \mathrm{~h}, p=0.015$ ). On the basis of the ROC curve, we defined an optimal cutoff of $24 \mathrm{~h}$, with which we divided the patients as follows: group 1 $(n=50)$ comprised patients with a DSOF $\leq 24 \mathrm{~h}$, and group $2(n=60)$ contained patients with a DSOF $>24 \mathrm{~h}$. There were statistically significant differences in the in-hospital mortality rate between the two groups (52.0\% vs. 25.0\%, $p=0.004)$. Furthermore, by multivariate analysis, DSOF $\leq 24 \mathrm{~h}$ (odds ratio: 5.89, 95\% confidence interval: $1.46-23.8, p=0.013$ ) was a significant independent prognostic factor.
\end{abstract}

Conclusion: DSOF may be a useful prognostic factor for severe sepsis.

Keywords: Severe sepsis, Septic shock, Systemic inflammatory response syndrome (SIRS), Organ failure, Acute Physiology and Chronic Health Evaluation (APACHE) II score

\section{Background}

The mortality rate of patients complicated with sepsisassociated organ failure or septic shock remains high in spite of the treatments in intensive care units (ICU) [1,2]. There are non-responders among the septic patients with poor prognosis whose disease progresses rapidly despite various treatments received in the ICU.

Previous reports show that certain scoring systems, including the Acute Physiology and Chronic Health Evaluation (APACHE) II score, Disseminated Intravascular Coagulation (DIC) score, Sequential Organ Failure Assessment (SOFA) score, and delta SOFA score, predict the prognosis of sepsis [3-5]. However, they sometimes fail to provide a prognosis for identifying high-risk patients with sepsis at an early stage [6,7].

\footnotetext{
* Correspondence: sugitaf@ba2.so-net.ne.jp

${ }^{1}$ Department of Gastroenterological Surgery, Graduate School of, Medical Sciences, Kumamoto University, 1-1-1 Honjo, Kumamoto 8608556, Japan Full list of author information is available at the end of the article
}

Sepsis is generally defined as systemic inflammatory response syndrome (SIRS) with infection [8]. In most cases of sepsis, patients only develop SIRS in the early stage, but some of them (approximately 25\%) progress to advanced stages of the disease, which entail organ failure and septic shock $[9,10]$. However, no study has sufficiently examined the speed of progression from early stage sepsis to organ failure and septic shock in the advanced stages. We defined a novel parameter-the duration of SIRS before organ failure (DSOF) - which denotes the speed of sepsis progression. The purpose of this study was to determine whether DSOF has prognostic value in septic patients complicated with organ failure or shock.

\section{Methods}

\section{Patients and definition}

This retrospective cohort study was conducted in the medical and surgical ICU of a university hospital. The 
institutional ethics committee approved this study, and all enrollees gave their informed consent. From September 2001 to February 2007, 118 patients were enrolled. They consist of the patients from the general ward of our hospital and patients from other hospitals. They were transferred to the ICU for treatment of sepsis.

Sepsis was defined as an infection with SIRS. Patients were classified according to the American College of Chest Physicians/Society of Critical Care Medicine Sepsis Consensus Conference, 1992 [11].

We defined SIRS as the presence of at least two of the following criteria: (1) body temperature $>38^{\circ} \mathrm{C}$ or $<36^{\circ} \mathrm{C}$, (2) heart rate $>90$ beats $/ \mathrm{min}$, (3) respiratory rate $>20$ breaths/min or $\mathrm{PaCo}_{2}<32 \mathrm{mmHg}$, and (4) WBC count $>12,000 / \mu \mathrm{l}$ or $<4,000 / \mu \mathrm{l}[8]$. When patients fulfilled the criteria of SIRS, the time was recorded as first recognition. Patients who needed to receive mechanical ventilation and/or had serum $\mathrm{Cr}$ levels above $4.0 \mathrm{mg} / \mathrm{dl}$ or total bilirubin levels above $5.0 \mathrm{mg} / \mathrm{dl}$ were considered to have respiratory failure, renal failure, or hepatic failure, respectively. The time of intubation or blood sampling was regarded as the first recognized time of organ failure. We defined shock as systolic blood pressure below $90 \mathrm{mmHg}$ or the necessity of the administration $>5 \mu \mathrm{gkg}^{-1} \mathrm{~min}^{-1}$ dopamine, dobutamine, or any dose of nor-adrenaline, even if sufficient fluids were infused. When patients fulfilled at least one of the criteria of organ failure or septic shock, the time was recorded as first recognition.

Any patient who was diagnosed with sepsis and admitted to the 11-bed medical and surgical ICU of Kumamoto University Hospital was enrolled in this study if he or she fulfilled the criteria for sepsis with organ failure or sepsis with shock. DSOF was defined as the duration from the initial recognition of SIRS to the first recognition of organ failure or shock (Figure 1) and was calculated on

\section{Progression of Infection}

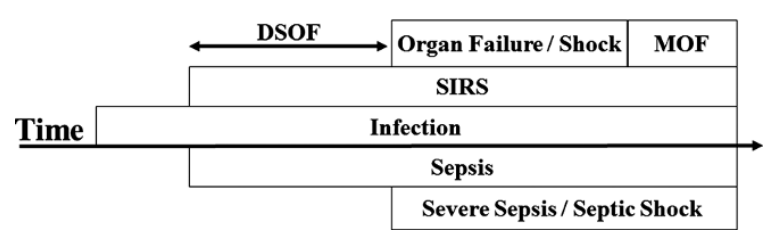

Figure 1 Schematic representation of the progressive course of infection. Sepsis without organ failure or shock in the early stage progresses to severe sepsis or septic shock in the advanced stage. Sepsis was defined as an infection with systemic inflammatory response syndrome (SIRS). Severe sepsis and septic shock were defined as sepsis with any organ failure and sepsis with shock, respectively. Duration of SIRS before organ failure (DSOF) was defined as the duration from the first recognition of SIRS to the first recognition of organ failure or septic shock. the basis of accurate medical records. Various data were recorded on recognition of organ failure or shock: gender; age; shock or not shock; underlying diseases; localization of the primary infection; whether the patient came from the general ward in our hospital or from another hospital; whether the patient was post-surgical; blood pressure; heart rate; respiratory rate; bacterial species; arterial blood gas, including $\mathrm{pH}$ and $\mathrm{PaO}_{2}$; and venous blood parameters. Neurological evaluations were performed using the Glasgow Coma Scale (GCS). APACHE II and SOFA scores were calculated as described [5,12]. We defined DIC per the revised criteria of the Japanese Association for Acute Medicine (JAAM) [13,14]. Various prognostic factors were evaluated for the endpoint of in-hospital mortality of the septic patients.

As the treatment of sepsis, removal or drainage of the infection sites and adequate antimicrobial therapy were performed as soon as possible [3,15-17]. Mechanical ventilation for sepsis-induced acute lung injury (ALI)/ acute respiratory distress syndrome (ARDS) and fluid resuscitation and the administration of catecholamine for maintaining circulation for septic shock are performed in septic patients to prevent the development of a more critical condition resulting in MOF and death [8,18-20]. The treatment of sepsis was performed according to the Surviving Sepsis Campaign guideline [8,21].

\section{Statistical analysis}

The relationship between risk factors and death was first examined by univariate analysis using the two-sample unpaired Student's $t$-test for parametric continuous variables, Mann-Whitney $U$-test for nonparametric continuous variables, and Pearson's chi-square test for categorical variables. Multivariate logistic regression was performed to determine independent risk factors for inhospital mortality. Risk factors with $p$-values $<0.2$ by univariate analysis were put into the multivariate logistic regression. The SOFA score was not included in the multivariate analysis because it has a relationship with APACHE II scores. We analyzed the survival between patients with DSOF $\leq 24$ h and DSOF $>24$ h by using Kaplan-Meier survival curves, and the significance was tested by log-rank test. All statistical analyses were performed using SPSS for Windows (Release 13.0; SPSS Inc., Chicago, IL). Two-tailed $p$-values $<0.05$ were considered significant.

\section{Results and discussion Results}

Of the 118 patients who were enrolled initially, we excluded 5 patients who had uncertain records regarding the first recognition of SIRS and 3 patients younger than 15 years. Thus, the final group for evaluation comprised 110 patients. The mean age of the patients (72 men and 38 women) was $63.3 \pm 1.4$ years (range $16-88$ years). 
There were 59 (53.6\%), 79 (71.8\%), and 28 (25.5\%) patients with shock, organ failure, and both, respectively. The types of organ failure were respiratory failure (70 patients), renal failure ( 8 patients), and hepatic failure ( 3 patients). The mean ICU and mean hospital stays were $15.5 \pm 2.4$ days and $54.1 \pm 5.0$ days, respectively. The mean APACHE II and SOFA scores at admission were $22.6 \pm 0.7$ and $8.92 \pm 0.38$, respectively. The mean and median DSOFs were $68.9 \pm 8.5 \mathrm{~h}$ and $28.5 \mathrm{~h}$ (range $0-456 \mathrm{~h}$ ), respectively. The in-hospital mortality rate was $36.9 \%$.
Table 1 shows the univariate analysis of various factors and variables as prognostic factors. As a metric variable, DSOF was a statistically significant prognostic factor, as were age, APACHE II score, SOFA score, AT III, BUN, and pneumonia.

Figure 2A shows the number of survivors and nonsurvivors for each DSOF value. The mortality rate was higher in patients with shorter DSOFs. The receiveroperating characteristic (ROC) curve and area under ROC curve (AUC) show that DSOF is a significant prognostic factor as are the APACHE II and SOFA scores.

Table 1 Univariate analysis of risk factors for in-hospital mortality

\begin{tabular}{|c|c|c|c|}
\hline Prognostic factor & Non-survivors $(n=41)$ & Survivors $(n=69)$ & $P$ value \\
\hline Gender (men) & $30(73.2)$ & $42(60.9)$ & 0.190 \\
\hline Age & $69.3 \pm 1.7$ & $59.7 \pm 1.8$ & 0.001 \\
\hline APACHE II score & $26.6 \pm 0.1$ & $20.3 \pm 0.8$ & $<0.001$ \\
\hline SOFA score & $10.1 \pm 0.7$ & $8.3 \pm 0.4$ & 0.040 \\
\hline DIC score & $4.5 \pm 0.32$ & $4.37 \pm 0.25$ & 0.776 \\
\hline Shock & $24(58.5)$ & $35(50.7)$ & 0.427 \\
\hline Underlying disease & $27(58.5)$ & $37(53.6)$ & 0.209 \\
\hline Chronic cardiac insufficiency & $3(11.1)$ & $3(7.9)$ & \\
\hline Diabetes mellitus & $4(14.8)$ & $9(23.7)$ & \\
\hline Hepatic cirrhosis & $6(22.2)$ & $6(15.8)$ & \\
\hline Immunosuppression & $8(29.6)$ & $10(26.3)$ & \\
\hline Neoplasm & $4(14.8)$ & $5(13.2)$ & \\
\hline Chronic renal insufficiency & $1(3.7)$ & $1(2.6)$ & \\
\hline Chronic pulmonary insufficiency & $1(3.7)$ & $3(7.9)$ & \\
\hline \multicolumn{4}{|l|}{ Localization of infection } \\
\hline Abdomen & $16(39.0)$ & $34(49.3)$ & \\
\hline Lung & $19(46.3)$ & $19(27.5)$ & 0.045 \\
\hline Soft tissue & $5(12.2)$ & $10(14.5)$ & \\
\hline Others & $1(2.4)$ & $6(8.7)$ & \\
\hline From the general ward in our hospital & $22(53.7)$ & $37(53.6)$ & 0.997 \\
\hline Post surgery & $8(19.5)$ & $21(30.4)$ & 0.209 \\
\hline First antibiotic sensitivity & $14 / 27(51.9)$ & $22 / 50(44.0)$ & 0.510 \\
\hline Time lag between first detection of SIRS and administration of antibiotics & $12.8 \pm 3.5$ & $21.5 \pm 6.4$ & 0.125 \\
\hline GCS & $11.0 \pm 0.6$ & $11.6 \pm 0.4$ & 0.432 \\
\hline BUN (mg/dl) & $43.3 \pm 4.2$ & $32.7 \pm 2.7$ & 0.012 \\
\hline $\mathrm{Cr}(\mathrm{mg} / \mathrm{dl})$ & $2.12 \pm 0.21$ & $1.64 \pm 0.17$ & 0.051 \\
\hline T-bilirubin (mg/dl) & $3.44 \pm 0.77$ & $2.70 \pm 0.57$ & 0.175 \\
\hline AT III (\%) & $47.6 \pm 3.1$ & $63.1 \pm 2.7$ & 0.001 \\
\hline Fibrinogen (mg/dl) & $412 \pm 33$ & $463 \pm 18$ & 0.295 \\
\hline Platelets $\left(\times 10^{4} / \mu \mathrm{l}\right)$ & $11.6 \pm 1.5$ & $13.6 \pm 1.6$ & 0.619 \\
\hline CRP $(\mathrm{mg} / \mathrm{dl})$ & $17.4 \pm 1.4$ & $16.6 \pm 1.1$ & 0.625 \\
\hline $\mathrm{Ht}(\%)$ & $31.0 \pm 1.2$ & $29.6 \pm 0.7$ & 0.422 \\
\hline DSOF (h) & $58.8 \pm 16.5$ & $74.7 \pm 9.6$ & 0.015 \\
\hline $\mathrm{DSOF}(\leq 24 \mathrm{~h})$ & $26(63.4)$ & $24(34.8)$ & 0.004 \\
\hline DSOF ( $\leq 48 \mathrm{~h})$ & $30(73.2)$ & $38(55.1)$ & 0.059 \\
\hline
\end{tabular}



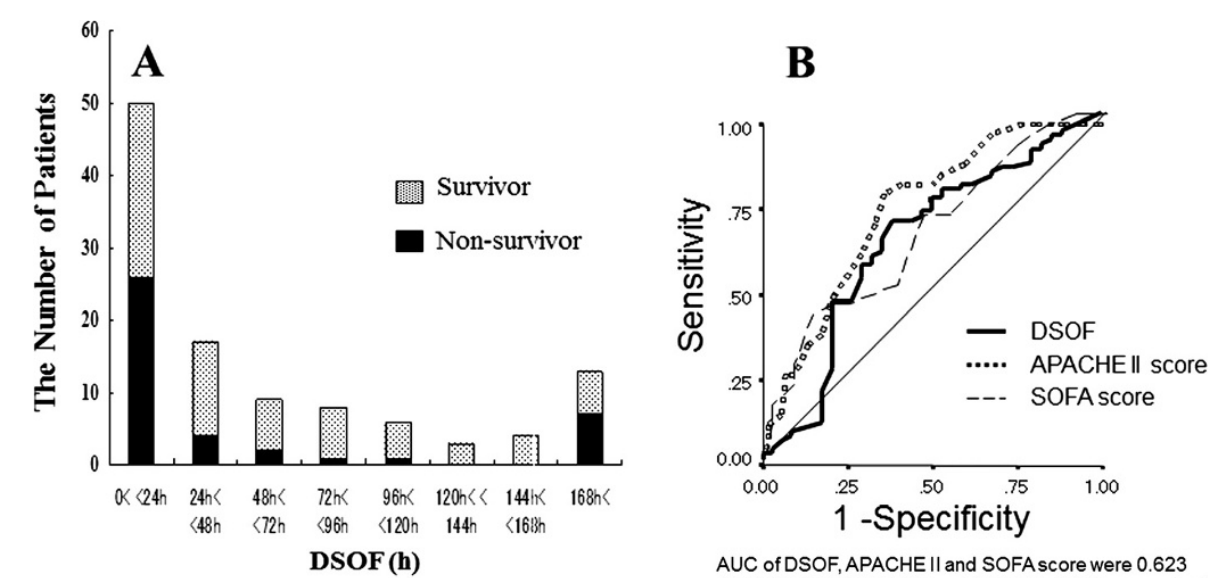

AUC of DSOF, APACHE II and SOFA score were 0.623 $(P=0.04), 0.748(P<0.01)$ and $0.664(P<0.01)$, respectively.

Figure 2 A. The number and mortality rates of patients by DSOF. B. ROC curve for DSOF, APACHE II, and SOFA scores for distinguishing non-survivors from patients with severe sepsis.

On the basis of the ROC curve, we defined the DSOF cutoff as $24 \mathrm{~h}$ (Figure 2B). Thus, we divided the patients into two groups: group 1 consisted of patients with a DSOF of $24 \mathrm{~h}$ or less $(\leq 24 \mathrm{~h})$, and group 2 comprised those with a DSOF of more than $24 \mathrm{~h}(>24 \mathrm{~h})$.

In-hospital mortality rates differed significantly between the two groups $(52.0 \%$ vs. $25.0 \%, p=0.004)$. Figure 3 shows the Kaplan-Meier survival curves. The mortality rate in group 1 was greater than that of group 2 (log rank test, $p<0.005)$.

Table 2 shows the characteristics of groups 1 and 2 . The mean age in group 1 was higher than in group 2 . SOFA scores and hematocrit, serum creatinine, and serum BUN levels in group 1 were significantly higher

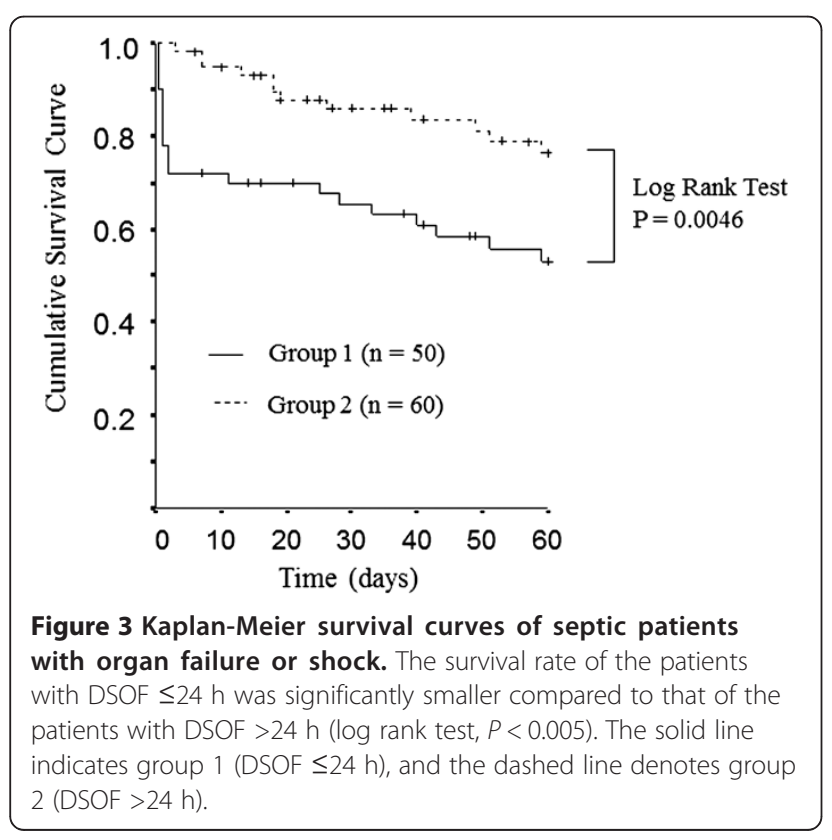

than in group 2. The incidence of septic shock was statistically greater in group 1 than in group 2 .

We analyzed the mortality rate in each subgroup on the basis of the primary infection site (Table 3 ). In patients with pneumonia, the in-hospital mortality rate in group 1 was significantly higher than in group 2 . In the other subgroups, the in-hospital mortality rate was generally higher in group 1 than in group 2 (not significant).

In the patients infected with E coli or Streptococcus spp., the incidence was significantly greater in group 1 than in group 2. Conversely, there were significantly fewer non-survivors than survivors among the patients who were infected with E coli, while those with Streptococcus spp. tended to have high mortality rates (Table 4).

Various prognostic factors were analyzed by multivariate analysis using logistic regression. Table 5 shows the independent prognostic factors at the time of recognition of organ failure or shock. DSOF $\leq 24 \mathrm{~h}$ (odds ratio: $5.37,95 \%$ confidence interval: $1.36-21.24, p=0.017$ ) was a significant prognostic factor of in-hospital mortality, as were APACHE II score, AT III levels, age, and pneumonia. As a metric variable, DSOF is not a statistically significant prognostic factor according to multivariate analysis.

\section{Discussion}

We developed and defined the DSOF-calculated using clinical parameters-and evaluated its value as a prognostic factor (Figure 1). Our results demonstrate that as a metric variable, DSOF is a significant prognostic factor by univariate analysis and that the in-hospital mortality rate in patients with DSOF $\leq 24 \mathrm{~h}$ is significantly higher than in those with DSOF $>24 \mathrm{~h}$. In addition, a DSOF of $\leq 24 \mathrm{~h}$ is an independent prognostic factor in septic patients, as are APACHE II score, AT III levels, age, and primary infection in the lung according to multivariate analysis. 
Table 2 Patient characteristics in groups 1 and 2

\begin{tabular}{|c|c|c|c|}
\hline Characteristic & Group $1(n=50)$ & Group $2(n=60)$ & $P$ value \\
\hline Age, years & $66.8 \pm 1.6$ & $60.3 \pm 2.1$ & 0.048 \\
\hline Gender (men) & $32(64.0)$ & $40(66.7)$ & 0.770 \\
\hline APACHE II score & $23.3 \pm 1.0$ & $22.1 \pm 0.9$ & 0.463 \\
\hline SOFA score & $9.88 \pm 0.51$ & $8.12 \pm 0.52$ & 0.014 \\
\hline DIC score & $4.47 \pm 0.28$ & $4.38 \pm 0.28$ & 0.798 \\
\hline Shock & $32(64.0)$ & $27(45.0)$ & 0.047 \\
\hline Severe underlying disease & $29(58.0)$ & $36(60.0)$ & 0.832 \\
\hline Chronic cardiac insufficiency & 1 & 5 & 0.145 \\
\hline Diabetes mellitus & 8 & 5 & 0.215 \\
\hline Hepatic cirrhosis & 8 & 4 & 0.118 \\
\hline Neoplasm & 3 & 6 & 0.446 \\
\hline Immunosupression & 6 & 12 & 0.259 \\
\hline Chronic renal insufficiency & 2 & 0 & 0.118 \\
\hline Chronic pulmonary insufficiency & 1 & 3 & 0.403 \\
\hline \multicolumn{4}{|l|}{ Localization of primary infection } \\
\hline Abdomen & $24(48.0)$ & $26(43.3)$ & 0.625 \\
\hline Lung & $13(26.0)$ & $25(41.7)$ & 0.085 \\
\hline Soft tissue & $9(18.0)$ & $6(10.0)$ & 0.223 \\
\hline Other & $4(8.0)$ & $3(5.0)$ & 0.521 \\
\hline AT III (\%) & $56.6 \pm 3.4$ & $57.9 \pm 2.9$ & 0.643 \\
\hline $\mathrm{Cr}(\mathrm{mg} / \mathrm{dl})$ & $2.28 \pm 0.21$ & $1.43 \pm 0.16$ & $<0.001$ \\
\hline BUN (mg/dl) & $41.9 \pm 3.6$ & $32.7 \pm 3.0$ & 0.018 \\
\hline
\end{tabular}

Group 1: patients with a DSOF of $24 \mathrm{~h}$ or less ( $\leq 24 \mathrm{~h})$; group 2: patients with a DSOF of more than $24 \mathrm{~h}(>24 \mathrm{~h})$.

There may be a time lag between true SIRS development and the recognition of SIRS. The time lag may be less than a few hours. This may be a limit of this study. However, no physician can know the true development of SIRS in clinical practice. Thus, we employed the recognition time of SIRS in the present study. DSOF denotes the speed of progression from early to advanced-stage sepsis. Various factors, including host defense and its response to infection, the strength of the bacterial toxin, and treatment efficacy, influence the DSOF. Severe underlying diseases and condition such as diabetes mellitus, liver cirrhosis, and immunosuppression are implicated in the patient's prognosis, although we did not observe any significance in this study $[10,15,22-26]$.

\section{Table 3 Mortality rate in subgroups}

\begin{tabular}{lccr}
\hline Origin of infection & Group $\mathbf{1}(\boldsymbol{n}=\mathbf{5 0})$ & Group 2 $(\boldsymbol{n = 6 0 )}$ & $\boldsymbol{P}$ value \\
\hline Pneumonia & $12 / 13(92.3)$ & $7 / 25(28.0)$ & $<\mathbf{0 . 0 0 1}$ \\
\hline Panperitonitis & $5 / 14(35.7)$ & $3 / 7(42.9)$ & 0.751 \\
\hline Biliary tract infection & $2 / 6(33.3)$ & $1 / 10(10)$ & 0.247 \\
\hline Necrotizing fasciitis & $5 / 8(62.5)$ & $0 / 2(0)$ & 0.114 \\
\hline Others & $3 / 9(33.3)$ & $3 / 16(18.8)$ &
\end{tabular}

Group 1: patients with a DSOF of $24 \mathrm{~h}$ or less $(\leq 24 \mathrm{~h})$.

Group 2: patients with a DSOF of more than $24 \mathrm{~h}(>24 \mathrm{~h})$.
Septic patients with long DSOFs might tolerate bacteria. However, the type of bacteria and toxin is implicated in the DSOF-based prognosis. For example, Streptococcus spp. infection caused a short DSOF and poor prognosis in this study. Thus, the DSOF might reflect the host response and the strength of the bacteria.

The wide range in DSOFs causes the difficulty in statistical evaluation. We defined an optimal cutoff of $24 \mathrm{~h}$ with which we divided the patients and compared mortality rates. Further, we compared the characteristics between groups 1 and 2 to determine the factors that influence the DSOF. Age might significantly influence DSOF. The higher incidence of shock in group 1 than group 2 suggests that the progression from SIRS to shock is more rapid than the progression from SIRS to organ failure. The deterioration of renal function in group 1 patients might be attributed to shock. Furthermore, the higher SOFA scores in group 1 might be attributed to renal dysfunction and shock.

We examined various prognostic factors of severe sepsis and septic shock by multivariate analysis and found that age, APACHE II score, AT III, and pneumonia are independent prognostic factors, consistent with previous reports $[2,3,10,27]$. Our results suggest that the DIC score at the time of ICU admission has no prognostic 
Table 4 Bacterial species and DSOF

\begin{tabular}{|c|c|c|c|c|c|c|}
\hline \multirow[t]{2}{*}{ Bacteria } & \multicolumn{3}{|c|}{ Number of patients } & \multicolumn{3}{|c|}{ Number of patients } \\
\hline & DSOF $\leq 24 \mathrm{~h}$ & DSOF $>24 h$ & $P$ & Non-survivor & survivor & $P$ \\
\hline$M R S A^{*}$ & 4 & 11 & & 5 & 10 & \\
\hline Streptococcus spp. & 8 & 2 & 0.04 & 7 & 3 & 0.07 \\
\hline Pseudomonas aeruginosa & 2 & 7 & & 5 & 4 & \\
\hline Escherchia coli & 7 & 1 & 0.016 & 0 & 8 & 0.02 \\
\hline Enterococcus spp. & 2 & 5 & & 2 & 5 & \\
\hline Vibrio vulnificus & 5 & 1 & 0.06 & 3 & 3 & \\
\hline Klebsiella spp. & 2 & 4 & & 2 & 4 & \\
\hline Enterobacter spp. & 1 & 4 & & 1 & 4 & \\
\hline Stenotrophomonas maltophilia & 2 & 2 & & 3 & 1 & \\
\hline Haemophilus influenzae & 1 & 1 & & 0 & 1 & \\
\hline Legionella pneumophila & 0 & 2 & & 0 & 2 & \\
\hline MSSA** & 0 & 2 & & 0 & 2 & \\
\hline Staphylococcus epidermidis & 2 & 0 & & 1 & 1 & \\
\hline Bacillus spp. & 1 & 0 & & 0 & 1 & \\
\hline Bacteroides spp. & 0 & 1 & & 0 & 1 & \\
\hline Corynebacterium spp. & 1 & 0 & & 1 & 0 & \\
\hline Morganella morganii & 0 & 1 & & 0 & 1 & \\
\hline Mycobacterium spp. & 0 & 1 & & 1 & 0 & \\
\hline Salmonella spp. & 0 & 1 & & 1 & 0 & \\
\hline Serratia marcescens & 0 & 1 & & 1 & 0 & \\
\hline Acinetobacter spp. & 1 & 0 & & 1 & 0 & \\
\hline Fungus & 2 & 5 & & 2 & 5 & \\
\hline Others & 2 & 1 & & 1 & 2 & \\
\hline Unknown & 11 & 8 & & 7 & 12 & \\
\hline Total & 53 & 61 & & 44 & 70 & \\
\hline
\end{tabular}

*MRSA: methicillin-resistant Staphylococcus aureus.

**MSSA: methicillin-sensitive Staphylococcus aureus.

value, although DIC has been reported to be a prognostic factor of organ failure [14,22]. These results indicate that the progression of DIC is slower than circulatory failure and respiratory failure in many cases and that early organ failure is not dependent on DIC. We

Table 5 Multivariate analysis of risk factors for in-hospital mortality

\begin{tabular}{lcc}
\hline Risk factor & In-hospital mortality OR (95\% Cl) & $\boldsymbol{P}$ Value \\
\hline DSOF $(\leq 24 \mathrm{~h})$ & $5.371(1.358-21.235)$ & $\mathbf{0 . 0 1 7}$ \\
\hline Pneumonia & $11.494(2.347-55.556)$ & $\mathbf{0 . 0 0 3}$ \\
\hline APACHE II score & $1.189(1.060-1.334)$ & $\mathbf{0 . 0 0 3}$ \\
\hline AT III & $0.956(0.923-0.991)$ & $\mathbf{0 . 0 1 3}$ \\
\hline Age & $1.068(1.014-1.125)$ & $\mathbf{0 . 0 2 1}$ \\
\hline Gender (female) & $0.388(0.101-1.381)$ & 0.153 \\
\hline T-bilirubin & $1.030(0.921-1.153)$ & 0.602 \\
\hline BUN & $0.994(0.961-1.028)$ & 0.717 \\
\hline Cr & $0.911(0.496-1.675)$ & 0.765 \\
\hline
\end{tabular}

analyzed DSOFs by the primary location of infection. In septic patients in whom the primary infection was the lung, DSOF $\leq 24 \mathrm{~h}$ was a significant prognostic factor of in-hospital mortality. However, our data show that the DSOF in patients with peritonitis was shorter than that in other subgroups, and the mortality rate in patients with DSOF $\leq 24 \mathrm{~h}$ is not greater than in patients with DSOF $>24 \mathrm{~h}$. These results indicate that pan-peritonitis progresses more rapidly than other diseases, and the patient's prognosis may depend on the surgical procedure and treatment after surgery. Analysis of a cohort of septic patients showing different types of sepsis may cause wide variations in DSOF. Thus, additional subgroup analyses are necessary.

DSOF may be dependent on the accuracy of the first detection of sepsis. Thus, the patients with infection should be observed carefully. However, the detection of SIRS in in-patients is not difficult. The Delta SOFA score, which measures the progression of organ failure, is an excellent prognostic factor, but it is not available 
until a few days after the patients have organ failure and have been admitted to the ICU $[28,29]$. In contrast, DSOF can be calculated at the time of recognition of organ failure. DSOF may be a promising prognostic factor for patients with severe sepsis. There is no correlation between the DSOF and APACHE II score. Thus, the combination of DSOF and APACHE II score may be more useful for determining the patients with poor prognosis.

\section{Conclusions}

DSOF may be a promising prognostic factor for the patients with severe sepsis. Further clinical studies are necessary.

\section{Competing interests}

The authors have no financial or other potential conflicts of interest to disclose.

\section{Authors' contributions}

HS thought up the design and carried out collection data, performed the statistical analysis, and drafted the manuscript. YK participated in its design and coordination. HB participated in drafting the manuscript. All authors read and approved the final manuscript.

\section{Author details}

'Department of Gastroenterological Surgery, Graduate School of, Medical Sciences, Kumamoto University, 1-1-1 Honjo, Kumamoto 8608556, Japan. ${ }^{2}$ Department of Aggressology and Critical Care Medicine, Graduate School of Medical Sciences, Kumamoto University, Kumamoto, Japan.

Received: 29 April 2012 Accepted: 10 December 2012

Published: 31 December 2012

\section{References}

1. Martin GS, Mannino DM, Eaton S, et al: The epidemiology of sepsis in the United States from 1979 through 2000. N Engl J Med 2003, 348:1546-1554.

2. Micek ST, Roubinian N, Heuring T, et al: Before-after study of a standardized hospital order set for the management of septic shock. Crit Care Med 2006, 34:2707-2713.

3. Garnacho-Montero J, Aldabo-Pallas T, Garnacho-Montero C, et al: Timing of adequate antibiotic therapy is a greater determinant of outcome than are TNF and IL-10 polymorphisms in patients with sepsis. Crit Care 2006, 10:R111.

4. Cauchie P, Cauchie C, Boudjeltia KZ, et al: Diagnosis and prognosis of overt disseminated intravascular coagulation in a general hospital meaning of the ISTH score system, fibrin monomers, and lipoprotein-Creactive protein complex formation. Am J Hematol 2006, 81:414-419.

5. Knaus WA, Draper EA, Wagner DP, et al: APACHE II: a severity of disease classification system. Crit Care Med 1985, 13:818-829.

6. Park BH, Park MS, Kim YS, et al: Prognostic utility of changes in N-terminal pro-brain natriuretic Peptide combined with sequential organ failure assessment scores in patients with acute lung injury/acute respiratory distress syndrome concomitant with septic shock. Shoc 2011, 36:109-114.

7. Charles PE, Ladoire S, Snauwaert A, et al: Impact of previous sepsis on the accuracy of procalcitonin for the early diagnosis of blood stream infection in critically ill patients. BMC Infect Dis 2008, 8:163.

8. Dellinger RP, Carlet JM, Masur H, et al: Surviving Sepsis Campaign guidelines for management of severe sepsis and septic shock. Crit Care Med 2004, 32:858-873.

9. Dremsizov T, Clermont G, Kellum JA, et al: Severe sepsis in communityacquired pneumonia: when does it happen, and do systemic inflammatory response syndrome criteria help predict course? Chest 2006, 129:968-978.

10. Alberti C, Brun-Buisson C, Chevret S, et al: Systemic inflammatory response and progression to severe sepsis in critically ill infected patients. Am J Respir Crit Care Med 2005, 171:461-468.
11. American College of Chest Physicians/Society of Critical Care Medicine Consensus Conference: Definitions for sepsis and organ failure and guidelines for the use of innovative therapies in sepsis. Crit Care Med 1992, 20:864-874.

12. Vincent $J$, de Mendonca A, Cantraine F, et al: Use of the SOFA score to assess the incidence of organ dysfunction/failure in intensive care units: results of a multicenter, prospective study. Working group on "sepsisrelated problems" of the European Society of Intensive Care Medicine. Crit Care Med 1998, 26:1793-1800

13. Gando S, Wada H, Asakura $H$, et al: Evaluation of new Japanese diagnostic criteria for disseminated intravascular coagulation in critically ill patients. Clin Appl Thromb Hemost 2005, 11:71-76.

14. Gando S, Iba T, Eguchi Y, et al: A multicenter, prospective validation of disseminated intravascular coagulation diagnostic criteria for critically ill patients: comparing current criteria. Crit Care Med 2006, 34:625-631.

15. Garnacho-Montero J, Garcia-Garmendia JL, Barrero-Almodovar A, et al: Impact of adequate empirical antibiotic therapy on the outcome of patients admitted to the intensive care unit with sepsis. Crit Care Med 2003, 31:2742-2751.

16. Marshall JC, Maier RV, Jimenez M, et al: Source control in the management of severe sepsis and septic shock: an evidence-based review. Crit Care Med 2004, 32:S513-S526.

17. Jimenez MF, Marshall JC: Source control in the management of sepsis. Intensive Care Med 2001, 27(Suppl 1):S49-S62.

18. Amato MB, Barbas CS, Medeiros DM, et al: Effect of a protective-ventilation strategy on mortality in the acute respiratory distress syndrome. $N$ Engl J Med 1998, 338:347-354.

19. LeDoux D, Astiz ME, Carpati CM, et al: Effects of perfusion pressure on tissue perfusion in septic shock. Crit Care Med 2000, 28:2729-2732.

20. Martin C, Viviand $X$, Leone $M$, et al: Effect of norepinephrine on the outcome of septic shock. Crit Care Med 2000, 28:2758-2765.

21. Rivers E, Nguyen B, Havstad S, et al: Early goal-directed therapy in the treatment of severe sepsis and septic shock. N Engl J Med 2001, 345:1368-1377.

22. Brun-Buisson C, Doyon F, Carlet J, et al: Incidence, risk factors, and outcome of severe sepsis and septic shock in adults. A multicenter prospective study in intensive care units. French ICU Group for Severe Sepsis. Jama 1995, 274:968-974.

23. Tsai MH, Peng YS, Chen YC, et al: Adrenal insufficiency in patients with cirrhosis, severe sepsis and septic shock. Hepatology 2006, 43:673-681.

24. Moreau R, Hadengue A, Soupison T, et al: Septic shock in patients with cirrhosis: hemodynamic and metabolic characteristics and intensive care unit outcome. Crit Care Med 1992, 20:746-750.

25. Thomsen RW, Hundborg HH, Lervang HH, et al: Diabetes mellitus as a risk and prognostic factor for community-acquired bacteremia due to enterobacteria: a 10-year, population-based study among adults. Clin Infect Dis 2005, 40:628-631.

26. Lujan M, Gallego M, Fontanals D, et al: Prospective observational study of bacteremic pneumococcal pneumonia: effect of discordant therapy on mortality. Crit Care Med 2004, 32:625-631.

27. Mesters RM, Mannucci PM, Coppola R, et al: Factor Vlla and antithrombin III activity during severe sepsis and septic shock in neutropenic patients. Blood 1996, 88:881-886.

28. Ferreira FL, Bota DP, Bross A, et al: Serial evaluation of the SOFA score to predict outcome in critically ill patients. JAMA 2001, 286:1754-1758.

29. Moreno $R$, Vincent $J L$, Matos $R$, et al: The use of maximum SOFA score to quantify organ dysfunction/failure in intensive care. Results of a prospective, multicentre study. Working Group on Sepsis related Problems of the ESICM. Intensive Care Med 1999, 25:686-696.

doi:10.1186/1865-1380-5-44

Cite this article as: Sugita et al.: The duration of SIRS before organ failure is a significant prognostic factor of sepsis. International Journal of Emergency Medicine 2012 5:44. 